\title{
Effects of Spaghetti Differing in Soluble Fiber and Protein Content on Glycemic Responses in Humans: A Randomized Clinical Trial in Healthy Subjects
}

\author{
Emilia Papakonstantinou ${ }^{1, * \mathbb{D}}$, Marina Xaidara ${ }^{1}$, Vassiliki Siopi ${ }^{1}$, Marianna Giannoglou ${ }^{2} \mathbb{D}$, George Katsaros $^{2} \mathbb{D}$, \\ Georgios Theodorou ${ }^{3}$ (D), Eirini Maratou ${ }^{4}$, Kalliopi-Anna Poulia ${ }^{1}$ (D), George D. Dimitriadis ${ }^{5}$ \\ and Panagiotis N. Skandamis ${ }^{6}$
}

check for updates

Citation: Papakonstantinou, E.; Xaidara, M.; Siopi, V.; Giannoglou, M.; Katsaros, G.; Theodorou, G.; Maratou, E.; Poulia, K.-A.; Dimitriadis, G.D.; Skandamis, P.N. Effects of Spaghetti Differing in Soluble Fiber and Protein Content on Glycemic Responses in Humans: A Randomized Clinical Trial in Healthy Subjects. Int. J. Environ. Res. Public Health 2022, 19, 3001. https:// doi.org/10.3390/ijerph19053001

Academic Editor: Alessandra Durazzo

Received: 6 January 2022 Accepted: 25 February 2022 Published: 4 March 2022

Publisher's Note: MDPI stays neutral with regard to jurisdictional claims in published maps and institutional affiliations.

Copyright: (C) 2022 by the authors. Licensee MDPI, Basel, Switzerland. This article is an open access article distributed under the terms and conditions of the Creative Commons Attribution (CC BY) license (https:// creativecommons.org/licenses/by/ $4.0 /)$.
1 Laboratory of Dietetics and Quality of Life, Department of Food Science and Human Nutrition, School of Food and Nutritional Sciences, Agricultural University of Athens, 11855 Athens, Greece; stud516028@aua.gr (M.X.); vickysiopi888@gmail.com (V.S.); lpoulia@gmail.com (K.-A.P.)

2 Institute of Technology of Agricultural Products, Hellenic Agricultural Organization "DEMETER", 14123 Athens, Greece; giannoglou@chemeng.ntua.gr (M.G.); gkats@chemeng.ntua.gr (G.K.)

3 Laboratory of Animal Breeding and Husbandry, Department of Animal Science, School of Animal Biosciences, Agricultural University of Athens, 11855 Athens, Greece; gtheod@aua.gr

4 Department of Clinical Biochemistry, "Attikon" University General Hospital, National and Kapodistrian University of Athens, Haidari, 12462 Athens, Greece; maratou@hotmail.com

5 Sector of Medicine, Medical School, National and Kapodistrian University of Athens, 15772 Athens, Greece; gdimitr@med.uoa.gr

6 Laboratory of Food Quality Control and Hygiene, Department of Food Science and Human Nutrition, School of Food and Nutritional Sciences, Agricultural University of Athens,

11855 Athens, Greece; pskan@aua.gr

* Correspondence: emiliap@aua.gr; Tel.: +30-2105294967

\begin{abstract}
This randomized, single blind, cross-over study investigated the glycemic responses to three spaghetti No 7 types differing in dietary protein and soluble fiber content. Fourteen clinically and metabolically healthy, fasting individuals (25 \pm 1 years; ten women; BMI $23 \pm 1 \mathrm{~kg} / \mathrm{m}^{2}$ ) received isoglucidic test meals (50 g available carbohydrate) and $50 \mathrm{~g}$ glucose reference, in random order. GI was calculated using the FAO/WHO method. Capillary blood glucose and salivary insulin samples were collected at 0, 15, 30, 45, 60, and $120 \mathrm{~min}$. Subjective appetite ratings (hunger, fullness, and desire to eat) were assessed by visual analogue scales (VAS, $100 \mathrm{~mm}$ ) at baseline and $120 \mathrm{~min}$. All three spaghetti types (regular, whole wheat, and high soluble fiber-low carbohydrates) provided low GI values $(33,38$, and 41, respectively, on glucose scale) and lower peak glucose values compared to glucose or white bread. No differences were observed between spaghetti No 7 types for fasting glucose, fasting and post-test-meal insulin concentrations, blood pressure (systolic and diastolic), and subjective appetite. Conclusions: all spaghetti No 7 types, regardless of soluble fiber and/or protein content, attenuated postprandial glycemic response, which may offer advantages to glycemic control.
\end{abstract}

Keywords: spaghetti; glycemic index; glycemic response; healthy; soluble fiber; protein; low carbohydrate; pasta

\section{Introduction}

It is well accepted that cereals and their products, particularly pasta, are the principal components of our diet. When starchy foods are consumed blood glucose rises; however, the extent of this rise (increment) depends on the amount of total carbohydrates consumed, the type of carbohydrate, and other components, such as soluble fiber, protein, and fat content of these foods, preparation method, cooking practices, etc. The glycemic index (GI) is a tool developed to systematically classify carbohydrate-containing foods according to time-integrated effects on postprandial glucose response [1,2]. GI is defined as the incremental area under the blood glucose curve (iAUC) elicited by a $50 \mathrm{~g}$ available carbohydrate 
portion of a food expressed as a percentage of that after $50 \mathrm{~g}$ carbohydrate from a reference food (typically D-glucose or white bread) taken by the same subject [3-5]. The starch of high GI foods is digested and absorbed rapidly from the human digestive system, which may lead to glucose spikes and troughs; whereas carbohydrates in foods with a low GI are slowly digested and absorbed, and as a result, diets with a low GI may be more beneficial in controlling postprandial plasma glucose excursions [6]. Increased glucose fluctuations have been shown to induce oxidative stress and $\beta$-cell damage [7]. Additionally, increased glucose variability from peaks to nadirs has been recognized as a major metabolic defect leading to cardiovascular diseases [8]. Consequently, foods containing rapidly digested, absorbed, and metabolized carbohydrates are considered high GI foods, whereas those containing slowly digested, absorbed, and metabolized carbohydrates are considered low GI foods (low GI: $\leq 55$, moderate GI: 56-69, high GI: $\geq 70$ on the glucose scale) [3]. The glycemic load (GL) is a mathematical equation considering the product of GI and the total available carbohydrate content in a food amount [3]. The GL of a food can be classified as low, medium, or high (low: $\leq 10$, medium: $11-19$, high: $\geq 20$ ). It has been proposed that the GL is a good predictor of postprandial glycemia associated with consuming a serving portion of a particular food [9]. It has been shown that regular consumption of high GI foods is associated with increased chronic disease risk [3,10,11], whereas low to moderate GI foods are considered favorable to health [2,12]. Replacement of higher GI with lower GI foods seems to offer a moderate improvement in glycemic control $[13,14]$. In some cohort studies, the GL, but not the carbohydrate content, has been frequently linked to a reduced risk of type 2 diabetes [10]. It has been proposed that lowering the GL of consumed carbohydrates may lead to a significant reduction in hemoglobin A1C from $-0.2 \%$ up to $-0.5 \%$ [14-16]. It should be noted however that other factors, such as the inclusion of soluble dietary fiber, resistant starch and amylose, and inclusion of non-cereal ingredients (i.e., oat fiber, flaxseed, legume-based flours, protein) may influence the glycemic responses [3,6,17-20]. We have shown in a series of studies that foods (such as Ceratonia siliqua, carob) and characteristics (such as large bran size in breads or the sucrose to oligosaccharide ratio in honey varieties of similar botanical origin and characterization explaining $30 \%$ of the postprandial glucose differences) are able to reduce glucose excursions and overall postprandial glycemic responses [21-23].

Spaghetti is a commonly consumed food, with GI values ranging from low to high (i.e., regular spaghetti ranging from 33 to 98; wholegrain spaghetti ranging from 53 to 101) $[18,24]$. Results from an interlaboratory study from seven research centers (Toronto, Canada; Lund, Sweden; Sydney, Australia; Milan, Italy; Dunedin, New Zealand; Trinidad, West Indies, and Potchefstroom, South Africa) found spaghetti to be a low GI food (mean value obtained from 6 centers $=47$ ), with ranging values of 36-70 [25]. Factors influencing the GI of spaghetti include the flour used, the thickness, the cooking time, other ingredients, such as proteins, soluble fiber or fat, production processes $[2,25,26]$, all of which may lead to differences in the size of starch gelatinization and GI values. Spaghetti products, particularly novel ones with non-cereal ingredients have a specific importance for Mediterranean agrifood production, as they may be richer in nutrients such as protein and fibers.

The aims of this study were to investigate the short-term effects of three types of spaghetti No 7 (regular spaghetti, wholegrain spaghetti, and spaghetti high in soluble fiber and low in carbohydrates) on postprandial glycemic responses.

\section{Materials and Methods}

\subsection{Subjects}

Fourteen healthy subjects (4 men, 10 women), between 18-55 years, were recruited by a variety of methods, including online advertisements and flyers and notices posted around the university campus. Subjects underwent an initial screening and measurements included anthropometry (height, weight, waist, and hip circumference), fat percentage via bioimpedance analysis (InBody 230), blood pressure (Omron, Intellisense, HEM-907, Omron Hellas, Athens, Greece), and fasting blood glucose via finger prick (MediSmart ${ }^{\circledR}$ 
Ruby glucose meter with a lancing device, Lilly-PHARMASERV SA, Athens, Greece). Additionally, a questionnaire on general health was completed. Subjects were non-smokers, had a healthy body mass index (BMI), a normal blood pressure, and no medical conditions (i.e., cardiovascular diseases, diabetes mellitus, polycystic ovary syndrome, liver diseases, nephropathy, clinical depression, gastrointestinal disorders), were not pregnant/lactating, or taking medications known to affect glycemia (glucocorticoids, metformin, thyroid hormones, thiazide diuretics), and were not allergic to the test foods. All fourteen subjects completed all treatments and were included for analysis.

The study was conducted at the Laboratory of Dietetics and Quality of Life, Agricultural University of Athens, Greece. All subjects gave their informed consent for inclusion before participating in the study. The study was conducted in accordance with the Declaration of Helsinki, and the protocol was approved by the Bioethics Committee of the Agricultural University of Athens (EIDE Reference Number: 2021/49). This trial was registered at Clinicaltrials.gov (NCT05197283).

\subsection{Study Design}

The glycemic indexes (GIs) of three commercial Spaghetti No 7 pasta samples (Melissa Kikizas S.A., Athens, Greece, brand called Melissa ${ }^{\circledR}$ ) were evaluated. The GI was determined according to ISO 26642:2010 [1], Brouns et al., (2005) [4], and the FAO/WHO (1998) [2] method and procedures. The study consisted of seven dietary treatments in a randomized, cross-over design: two glucose reference drinks, two white bread (WB) reference foods, a semolina spaghetti No 7 (S; Athens, Greece, Melissa ${ }^{\circledR}$ ), a wholegrain spaghetti No 7 (WS; Athens, Greece, Melissa ${ }^{\circledR}$ ), and a semolina spaghetti No 7 high in soluble fiber and low in carbohydrates (HFlowCS; Athens, Greece, Melissa ${ }^{\circledR}$ ). Subjects attended seven test sessions of around $3 \mathrm{~h}$, separated by a wash-out period of at least two days. Each test session consisted of a test meal that had to be consumed within $15 \mathrm{~min}$ and $2 \mathrm{~h}$ post-consumption measurement of metabolic blood parameters. Subjects arrived at the test center around 08:45-9:00 $\mathrm{h}$ in the morning following an overnight fast of 10-14 $\mathrm{h}$. In addition, subjects were instructed to refrain from strenuous physical activity and alcohol on the day before the test and were only allowed to eat the provided foods throughout the test sessions. Online computer software (Social Psychology Network, Middletown, CT, USA) was used for simple randomization of the sequence of the test foods (http:/ / www.randomizer.org/ (accessed on 1 April 2020) [27]. A researcher not involved in the collection and analysis of the scientific data, was responsible for the randomization of the volunteers to the intervention days examining the test foods. Subjects received, in a random order, the reference food (D-glucose), tested twice (i.e., 1st 4th visit) and white bread (WB), tested twice (i.e., 2nd and 5th visit) (Figure 1), and the three spaghetti products: S, WS, and HFLowCS, tested once, in different weeks, with a random sequence in accordance with the recommended GI methodology [1,2].

\subsection{Test Meals}

During each of the seven test sessions, subjects consumed one of the following test meals: S made with durum hard wheat semolina flour (Melissa ${ }^{\circledR}$, Athens, Greece), WS made with wholegrain hard wheat flour (Melissa ${ }^{\circledR}$, Athens, Greece), HFlowCS made with durum hard wheat semolina flour, rice bran, oat fibers, and flaxseed flour (Melissa ${ }^{\circledR}$, Athens, Greece), or glucose reference drink ( $50 \mathrm{~g}$ anhydrous glucose dissolved in $250 \mathrm{~mL}$ water), or white bread as a second reference food. All the test foods and the reference foods were given in portions containing $50 \mathrm{~g}$ available carbohydrates. Regarding the pasta samples, the available carbohydrates were determined at the final cooked product (ready to eat boiled pasta), since it is known that the composition of pasta is significantly altered during boiling due to cooking losses [28]. Unsalted boiling water was chosen to cook the pasta to the recommended by the producer cooking times (i.e., recommended 8-9 min for S, selected: $8.5 \mathrm{~min}$; recommended 9-10 $\mathrm{min}$ for WS, selected: $9.5 \mathrm{~min}$; and recommended 8-9 min for HFlowCS, selected: 8.5 min cooking time). The total meal characteristics and 
macronutrients composition of the dried test foods based on their food label is shown in Table 1. The nutritional characteristics of the studied pasta products were evaluated in terms of their total protein content (Kjeldahl AACC 47-12), ash content (AOAC 923.03), moisture (AOAC 930.15), available carbohydrates, and total dietary fibers (Megazyme kit-K-ACHDF, Megazyme Ltd., Scotland, UK) (Table 2), as a function of their cooking time (based on the recommended cooking times of the producer). The portions of spaghetti were quickly served without adding cheese or any sauce. Portion sizes served for the test meal were based on the consumption of $50 \mathrm{~g}$ of products' available carbohydrates after boiling (163.67 g portion size for boiled S; $186.26 \mathrm{~g}$ portion size for boiled WS; $223.06 \mathrm{~g}$ portion size for boiled HFlowCS) and for WB (91.40 g). The available carbohydrates were determined with the aforementioned Megazyme kit, which calculates only the carbohydrates that can be absorbed (sugars and digestible starch), neglecting dietary fiber and resistant starch.

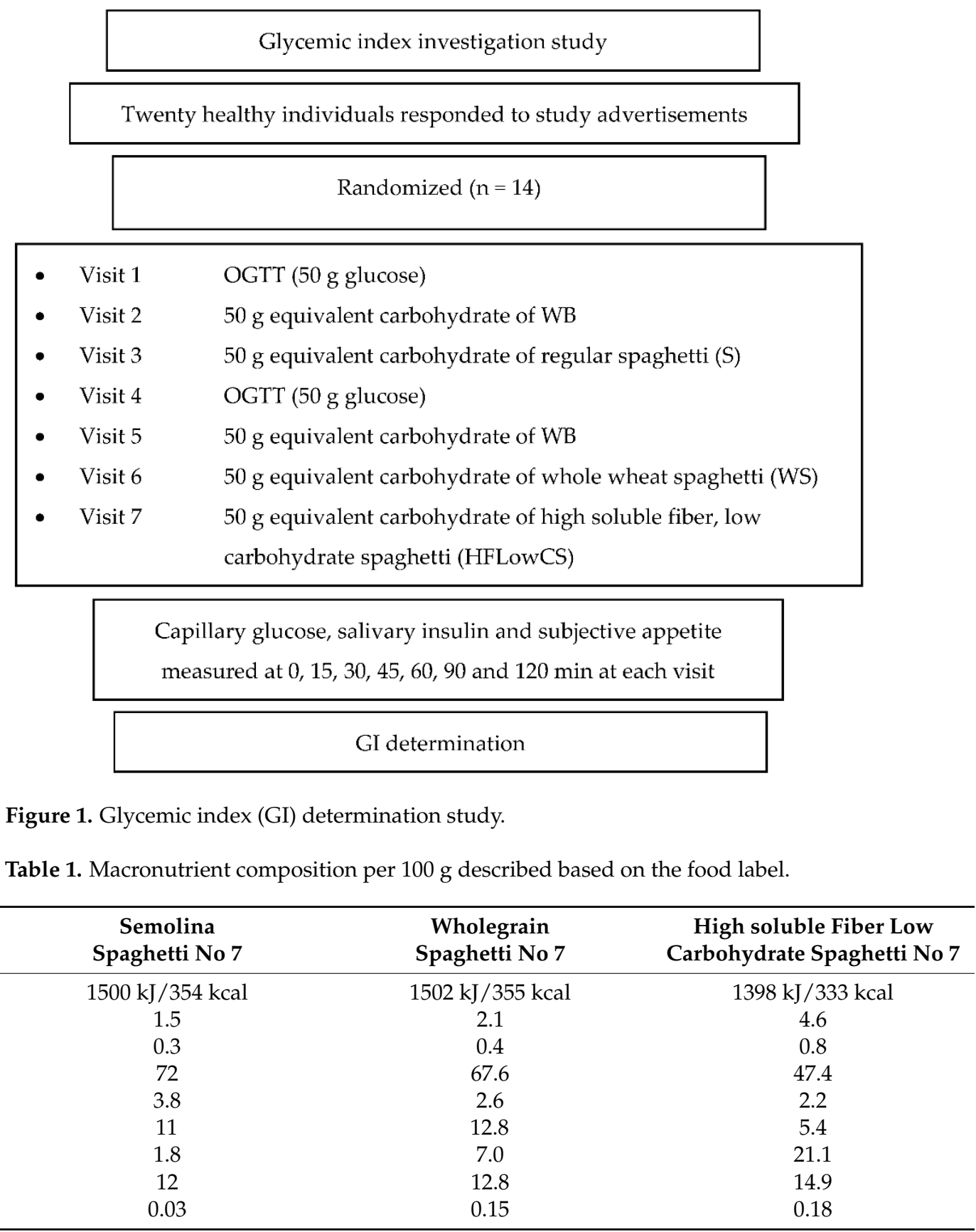


Table 2. Nutritional analysis of test spaghetti meals.

\begin{tabular}{|c|c|c|c|c|c|c|}
\hline $\begin{array}{l}\text { Spaghetti } \\
\text { Type }\end{array}$ & & $\begin{array}{c}\text { Cooking } \\
\text { Time* (min) }\end{array}$ & $\begin{array}{l}\text { Protein Content } \\
\text { (\%DM) }\end{array}$ & $\begin{array}{l}\text { Ash Content } \\
\text { (\%DM) }\end{array}$ & $\begin{array}{c}\text { Available } \\
\text { Carbohydrates } \\
\text { (\%DM) }\end{array}$ & $\begin{array}{c}\text { Total Dietary } \\
\text { Fibers } \\
\text { (\%DM) }\end{array}$ \\
\hline \multirow{4}{*}{ Spaghetti } & Raw & & $10.16 \pm 0.15^{a * *}$ & $0.93 \pm 0.04^{\mathrm{a}}$ & $84.99 \pm 1.65^{\mathrm{a}}$ & $1.82 \pm 0.08^{a}$ \\
\hline & \multirow{3}{*}{ Cooked } & 8.0 & $7.20 \pm 0.11^{b}$ & $0.66 \pm 0.02^{b}$ & $84.04 \pm 1.29^{a}$ & $1.79 \pm 0.06^{\mathrm{a}}$ \\
\hline & & 8.5 & $6.98 \pm 0.13^{c}$ & $0.62 \pm 0.02^{b, c}$ & $83.01 \pm 1.56^{a}$ & $1.77 \pm 0.07^{\mathrm{a}}$ \\
\hline & & 9.0 & $6.63 \pm 0.12^{d}$ & $0.59 \pm 0.03^{c}$ & $81.74 \pm 1.83^{a}$ & $1.79 \pm 0.04^{\mathrm{a}}$ \\
\hline \multirow{4}{*}{$\begin{array}{l}\text { Wholegrain } \\
\text { Spaghetti }\end{array}$} & Raw & & $14.97 \pm 0.13^{a}$ & $1.65 \pm 0.05^{\mathrm{a}}$ & $75.94 \pm 1.15^{\mathrm{a}}$ & $7.04 \pm 0.06^{\mathrm{a}}$ \\
\hline & \multirow{3}{*}{ Cooked } & 9.0 & $13.43 \pm 0.10^{b}$ & $1.24 \pm 0.01^{b}$ & $75.43 \pm 1.53^{a}$ & $7.01 \pm 0.05^{\mathrm{a}}$ \\
\hline & & 9.5 & $13.26 \pm 0.07^{b}$ & $1.22 \pm 0.01^{b, c}$ & $74.99 \pm 1.66^{\mathrm{a}}$ & $6.96 \pm 0.07^{a}$ \\
\hline & & 10.0 & $12.79 \pm 0.08^{c}$ & $1.21 \pm 0.01^{\mathrm{c}}$ & $73.75 \pm 1.27^{\mathrm{a}}$ & $6.99 \pm 0.05^{\mathrm{a}}$ \\
\hline \multirow{4}{*}{$\begin{array}{l}\text { High soluble } \\
\text { Fiber low } \\
\text { Carbohydrate } \\
\text { Spaghetti }\end{array}$} & Raw & & $12.39 \pm 0.09^{a}$ & $3.22 \pm 0.03^{a}$ & $55.16 \pm 1.62^{a}$ & $21.13 \pm 0.09^{a}$ \\
\hline & \multirow{3}{*}{ Cooked } & 8.0 & $10.57 \pm 0.12^{b}$ & $3.05 \pm 0.02^{b}$ & $55.04 \pm 1.48^{a}$ & $21.05 \pm 0.06^{\mathrm{a}}$ \\
\hline & & 8.5 & $10.04 \pm 0.10^{c}$ & $3.03 \pm 0.01^{b, c}$ & $54.78 \pm 1.55^{\mathrm{a}}$ & $21.08 \pm 0.06^{a}$ \\
\hline & & 9.0 & $9.34 \pm 0.10^{d}$ & $2.82 \pm 0.03^{c}$ & $52.04 \pm 1.59^{a}$ & $20.89 \pm 0.05^{a}$ \\
\hline
\end{tabular}

Subjects rated their hunger, desire to eat, and perceived fullness after eating on $100 \mathrm{~mm}$ line visual analogue scales (VAS), ranging from not at all $(0 \mathrm{~mm})$ to extremely $(100 \mathrm{~mm})$, with for example neither hungry $(0 \mathrm{~mm})$, full $(100 \mathrm{~mm})$, or having desire for food in the middle $(50 \mathrm{~mm})$. VAS were given in the form of a booklet, one scale per page [29]. VAS ratings were obtained at times $0,15,30,45,60,90$, and 120 min post-test meal consumption.

\subsection{Blood Glucose and Salivary Insulin Concentrations}

After a fasting blood sample, subjects ate a test meal at a comfortable pace within $15 \mathrm{~min}$ and had further blood samples at 15, 30, 45, 60, 90, and $120 \mathrm{~min}$ after starting to eat. Participants were instructed to consume the glucose drink at a comfortable pace within $10 \mathrm{~min}$. Test meals were served with $300 \mathrm{~mL}$ water as a drink in all seven trials.

To determine blood glucose concentrations, trained individuals from our research team, performed the capillary blood glucose monitoring procedure by skin pricking according to the scheduled time. To standardize all data collection procedures, capillary blood glucose monitoring was performed at the fingertip (distal phalange of the third finger). Capillary blood samples were collected at baseline (time 0 ) and at 15, 30, 45, 60, 90, and 120 min after test food or white bread or D-glucose consumption. Blood glucose was measured with glucose dehydrogenase-FAD test strips (Ruby Blood glucose Test Strips, Lilly-PHARMASERV SA, Athens, Greece), which show no reactivity to any sugars other than glucose and have better heat resistance and oxygen resistance. The allowed deviation limits of glucose meters for glucose results $\geq 100 \mathrm{mg} / \mathrm{dL}$ were within $15 \%$ of the reference method. The coefficient of variation $(\mathrm{CV}, \%)$ was less than $5 \%$ both in intermediate precision and repeatability. The blood glucose value recorded was the mean of three measurements.

The measured glycemic values were used to build the curve of the glycemic response for every volunteer and for every tested food, including the reference foods. Then, for each sample and each study subject, iAUC was calculated geometrically, using the trapezoid rule, and ignoring the area beneath the baseline [1,2]. The GI calculation for each pasta sample used the method referred to as the mean of the ratios. For each subject, the ratio between the individual iAUC after consuming the pasta sample and the iAUC for the same subject after consuming the reference foods was calculated and expressed as a percentage value. Then, the GI of each spaghetti type was calculated as the average value of the ratios 
across all the subjects consuming the pasta sample [1,2]. The mean, s.d., and coefficient of variation $(\mathrm{CV}=100 \mathrm{X}$ s.d./mean) of the AUC of each subject's repeated glucose (reference food) were calculated. The GL (g glucose equivalents)/1000 kJ values were calculated by multiplying the amount of carbohydrate contained in a $1000 \mathrm{~kJ}$ portion of that food $(53.09 \mathrm{~g}$ available carbohydrate in boiled S; $47.41 \mathrm{~g}$ available carbohydrate in boiled WS and $37.20 \mathrm{~g}$ available carbohydrate in boiled HFLowCS), which was then divided by 100.

To determine salivary insulin concentrations, salivary samples using the Salivette method (Sarstedt AG and Co., Numbrecht, Germany) were taken at baseline and at 15, 30, 45, 60, 90 and 120 min after meal consumption. Before the collection of samples, volunteers washed their mouths with clear water to avoid food contamination. Then, they were asked to remove the cotton from the tube and press it with their tongue for approximately $1 \mathrm{~min}$ to collect saliva from all glands. The tubes were centrifuged ( $3000 \times g$ for $5 \mathrm{~min}$ ) and stored at $-80^{\circ} \mathrm{C}$. Salivary insulin concentrations were determined using the Human Insulin ELISA Kit (ALPCO, 80-INSHU-E10.1, Salem, NH, USA) based upon a sandwich-type enzymelinked immunosorbent method. Plasma insulin and salivary insulin have been found to be significantly correlated $(r=0.882, p<0.001)$ [30].

\subsection{Blood Pressure Measurements and Dietary Intake Analysis}

Blood pressure (BP; systolic and diastolic) was measured the beginning and end of each intervention using an upper arm digital BP monitor (Omron, HEM-907, Omron Hellas, Athens, Greece). Participants were rested for $5 \mathrm{~min}$ in the supine position after which three BP measurements were taken at 1 min intervals, with the three readings averaged.

Dietary intake was assessed by $24 \mathrm{~h}$ recalls at every visit, and analyzed using the Diet Analysis Plus program, as well as using Hellenic and European Food Composition Databases (http: / / www.eurofir.org/foodinformation/ food-composition-databases-2/ (Accessed on 1 April 2020). The databases were modified to include new foods and recipes.

\subsection{Statistical Analysis}

Data distribution was tested using kernel density plots. Normally distributed continuous variables are presented as the mean values \pm standard error of the mean (SEM), unless otherwise stated, and the skewed as median (first tertile, third tertile). Differences in baseline continuous variables were evaluated using analysis of variance (ANOVA) for normally distributed continuous variables, Kruskal-Wallis test for skewed continuous data, and Pearson chi-square test for categorical variables. According to the ISO method 26642:2010 for GI calculation [1,2], we tested for outlying GI values in order to be excluded from the analysis. Between treatments, ANOVA for a $2 \times 2$ crossover study was conducted for blood glucose and salivary insulin. In a $2 \times 2$ design, we assume that there are no group effects since a complete randomization process was followed for treatment allocation. The models included the factors "subject" (id), "sequence" for inter-subject variation, and "period" and "treatments" to account for intra-subject variability. Time $\times$ test meal interaction was evaluated. Multiple comparisons between the interventions were tested post hoc using the Tukey test with Bonferroni correction. For all other parameters, one-way ANOVA was used to investigate differences between test meals followed by post hoc Tukey test and Bonferroni correction. Differences in VAS ratings were evaluated using one-way ANOVA and Friedman's test. Correlations between GI and the characteristics of the test meals were determined with Spearman's rho coefficient. The intervention trials were designed to have $80 \%$ power to detect a clinical difference of $25 \%$ for $0-120 \mathrm{~min}$ iAUC for blood glucose between the test and reference meals $(\alpha=0.05)$. A total of ten volunteers were required for the reference and test meals to achieve the power and clinical difference. In our study, 14 participants were recruited, and each participant served as a control for themselves. Statistical significance was determined to be $p<0.05$. All analyses were performed using SPSS software (version 23.0, SPSS Inc., Chicago, IL, USA). 


\section{Results}

\subsection{Subjects' Characteristics}

The subjects' characteristics can be found in Table 3. There were no intermittent missing values or dropouts.

Table 3. Baseline participants' characteristics $(n=14)$.

\begin{tabular}{cc}
\hline Characteristics & Total \\
\hline N & 14 (4 men, 10 women) \\
Age (years) & $25.21 \pm 0.91$ \\
Weight $(\mathrm{kg})$ & $64.51 \pm 4.44$ \\
Height (cm) & $167.43 \pm 0.10$ \\
Body mass index (BMI; kg/m²) & $22.67 \pm 0.89$ \\
Basal metabolic rate (BMR, kcal) & $1534.46 \pm 143.92$ \\
Body fat (kg) & $14.78 \pm 1.62$ \\
Muscle mass (kg) & $27.16 \pm 2.28$ \\
Waist circumference (cm) & $77.54 \pm 2.98$ \\
Hip circumference (cm) & $105.89 \pm 7.36$ \\
\hline Dietary intake (from 24-h recall) & \\
\hline Protein (gr) & $67.0 \pm 7.662$ \\
Carbohydrate (gr) & $206.27 \pm 21.28$ \\
Fat (gr) & $65.17 \pm 7.51$ \\
Saturated fat (gr) & $21.58 \pm 2.71$ \\
Total cholesterol(gr) & $218.74 \pm 26.99$ \\
Fiber (gr) & $18.06 \pm 1.96$ \\
Sodium (gr) & $2648.74 \pm 509.83$ \\
Energy intake (kcal) & $1668.85 \pm 165.97$ \\
\hline
\end{tabular}

Values are means \pm SEM or median (first, third tertile).

\subsection{Glycemic Index (GI) of Three Spaghetti Types}

The results of GI and GL for the three spaghetti test meals are presented in Table 4. The results revealed, similar GI values for the three tested samples (Table 4). According to the current classification [1,2], all three pastas should be considered low GI starchy foods. Based on the results, cooking led to a slight but statistically significant decrease in total proteins and minerals (ash content). In contrast, the bioavailable carbohydrates and the total dietary fiber content did not present significant differences compared to the raw product $(p>0.05)$. After statistical analysis, two individual GI values out of $98(0.02 \%)$ overcoming the mean by at least 2 SD were excluded from the mean calculation, as specified in the ISO methodology [1,2]. GL values were calculated for $1000 \mathrm{~kJ}$ and not related to portion, as previously suggested [18] because it is difficult to define the serving size for each item since portion sizes vary markedly among food industries and consumers. Expression of the effect of foods on postprandial glycemia on an isoenergetic basis is a logical and practical approach [18]. Compared to glucose and WB, all three spaghetti types, S, WS, and HFLowCS, had significantly lower GI and GL values, without significant differences between them $(p>0.05$; Table 4$)$.

\subsection{Blood Glucose and Salivary Insulin Concentrations}

The change in postprandial glucose and insulin over time $(120 \mathrm{~min})$ can be seen in Figure 2A,B. No significant differences were observed in fasting glucose concentrations between glucose and WB and the test meals ( $p$ for all $>0.05$; Figure $2 \mathrm{~A}$ ). There was a significant blood glucose $x$ time $x$ test meal interaction $(\mathrm{F}(36,690)=4.704, p<0.001)$. There was a significant main effect of test meal on blood glucose concentrations $(F(6,115)=12.387$, $p<0.001)$. Compared to the reference food (D-glucose), lower blood glucose concentrations were observed after the consumption of WB at $15 \mathrm{~min}, 30 \mathrm{~min}, 45 \mathrm{~min}$, and $60 \mathrm{~min}$ ( $p$ for all <0.001). It is clear that all three spaghetti test meals resulted in lower glucose, but not insulin, responses over time compared to the reference foods. In particular, the 
glucose concentrations were lower at 15, 30, 45, and 60 min after the start of the meal for all three spaghetti test meals as compared to the reference food (D-glucose) ( $p$ for all $<0.001$ ), without differences between them (Figure 2A). Compared to the reference food (D-glucose), lower blood glucose concentrations were observed after the consumption of $\mathrm{S}$ and WS at $90^{\prime}$ ( $p$ for all <0.001; Figure 2A), and higher for WS at $120^{\prime}(p=0.021$; Figure 2A). Compared to WB, lower blood glucose concentrations were observed after the consumption only of $\mathrm{S}$ at $30^{\prime}$ ( $p=0.009$; Figure 2A) and 120' $(p=0.043$; Figure 2A). Compared to $\mathrm{WB}$, lower blood glucose concentrations were observed after the consumption of S, WS, and HFLowCS at 45' ( $p=0.001, p=0.004$ and $p=0.027$, respectively; Figure 2A), $60^{\prime}(p<0.001, p=0.001$ and $p=0.017$, respectively; Figure $2 \mathrm{~A})$ and $90^{\prime}(p=0.004, p=0.010$ and $p=0.028$, respectively; Figure 2A). Peak glucose values were significantly lower for all three spaghetti food products compared to the reference food (D-glucose) or to the WB ( $p$ for all <0.001) (Table 4). S produced a significantly lower peak glucose value compared to WS and HFlowCS, without significant differences between the WS and HFlowCS (Table 4). The 0-120 min iAUC for blood glucose values calculated for each test meal are shown in Table 4 . There was a significant main effect of test meal on 0-120 min iAUC for blood glucose $(\mathrm{F}(6,117)=8.886, p<0.001)$. The mean within-individual variation of $0-120 \mathrm{~min}$ iAUC for blood glucose for the repeated tests was 36\%. The $0-120 \mathrm{~min}$ iAUC for blood glucose values calculated for WB, S, WS, and HFLowCS were significantly lower than those of the reference food (D-glucose) ( $p$ for all <0.05), without significant differences between them (Table 4). The 0-120 min iAUC for blood glucose values calculated only for $S$ were significantly lower than those of the reference food (WB) $(p=0.036$; Table 4). No significant differences were observed for salivary insulin concentrations between meals, compared to the reference food (D-glucose) and WB at all time points ( $p$ for all $>0.05$; Figure $2 \mathrm{~B}$ ). No differences were observed for 0-120 min iAUC for salivary insulin, peak salivary insulin value, and time to peak salivary insulin value (Table 4, Figure 2B).

Table 4. Incremental area under the curve (iAUC) for blood glucose, glycemic index (GI) and glycemic load (GL) of three spaghetti food products, relative to the reference D-glucose and white bread (WB).

\begin{tabular}{|c|c|c|c|c|c|c|}
\hline $\begin{array}{l}\text { Food (Serving } \\
\text { Size Containing } \\
50 \text { g Available } \\
\text { Carbohydrates) }\end{array}$ & $\begin{array}{l}\text { iAUC (mmol } \\
\left.120 \operatorname{min~}^{-1}\right)\end{array}$ & $\begin{array}{l}\text { GI (Glucose as } \\
\text { Reference Food) }\end{array}$ & $\begin{array}{c}\text { GI } \\
\text { (WB as } \\
\text { Reference Food) }\end{array}$ & $\begin{array}{l}\text { GL (Glucose as } \\
\text { Reference Food) }\end{array}$ & $\begin{array}{c}\text { GL } \\
\text { (WB as } \\
\text { Reference Food) }\end{array}$ & $\begin{array}{r}\text { Glucose Peak } \\
\text { Value (mg/dL) }\end{array}$ \\
\hline Glucose & $4478 \pm 228^{a}$ & $100^{a}$ & - & - & _- & $79.63 \pm 4.23^{a}$ \\
\hline WB & $3415 \pm 228^{b}$ & $73.55 \pm 5.47^{b}$ & - & $36.77 \pm 2.74^{b}$ & - & $55.79 \pm 3.53^{b}$ \\
\hline$S(163.67 \mathrm{~g})$ & $2144 \pm 324^{c}$ & $32.97 \pm 4.29^{c}$ & $46.26 \pm 5.24$ & $17.48 \pm 2.28^{c}$ & $24.52 \pm 2.78$ & $32.63 \pm 4.23^{c}$ \\
\hline WS (186.26 g) & $2547 \pm 324^{b, c}$ & $38.31 \pm 3.77^{c}$ & $48.84 \pm 4.81$ & $18.00 \pm 1.77^{c}$ & $22.95 \pm 2.26$ & $37.44 \pm 4.67^{b}$ \\
\hline $\begin{array}{l}\text { HFLowCS } \\
(223.06 \mathrm{~g})\end{array}$ & $2567 \pm 324^{b, c}$ & $40.55 \pm 4.37^{c}$ & $47.33 \pm 4.35$ & $15.00 \pm 1.62^{c}$ & $17.51 \pm 1.61$ & $39.57 \pm 3.95^{b}$ \\
\hline
\end{tabular}

Data are the means \pm SEM. Each value represents the mean of fourteen replicates. Abbreviations: WB: white bread; S: durum semolina wheat spaghetti; WS: wholegrain spaghetti; HFLowCS: high soluble fiber low carbohydrate spaghetti. Values marked with the same superscript letter are not significantly different $(p>0.05)$. Means were compared column-wise by using one-way ANOVA for factor "treatment", period and sequence of treatment, and post hoc Tukey test with Bonferroni correction to account for multiple comparisons between test meals; $p$-values $<0.05$ were considered as significant. To convert $\mathrm{mg} / \mathrm{dl}$ to $\mathrm{mmol} / \mathrm{L}$, values need to be divided by the number 18 .

\subsection{Blood Pressure and Subjective Appetite}

No differences were observed for subjective appetite assessment variables or BP measurements (systolic and diastolic) between meals compared to the reference food (D-glucose) and WB at all time points ( $p$ for all $>0.05$ ) (data not shown). 


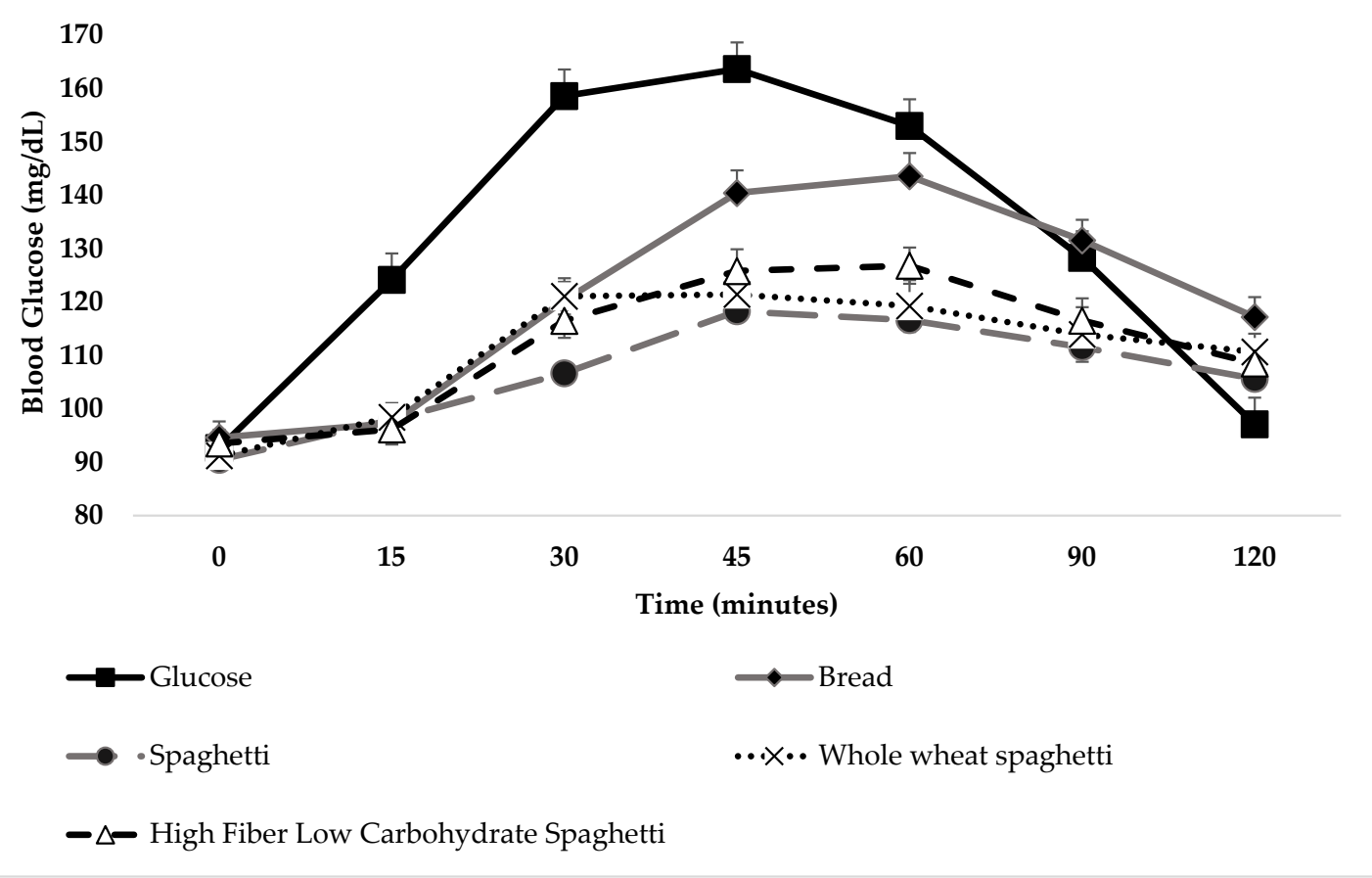

(A)

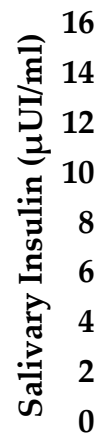
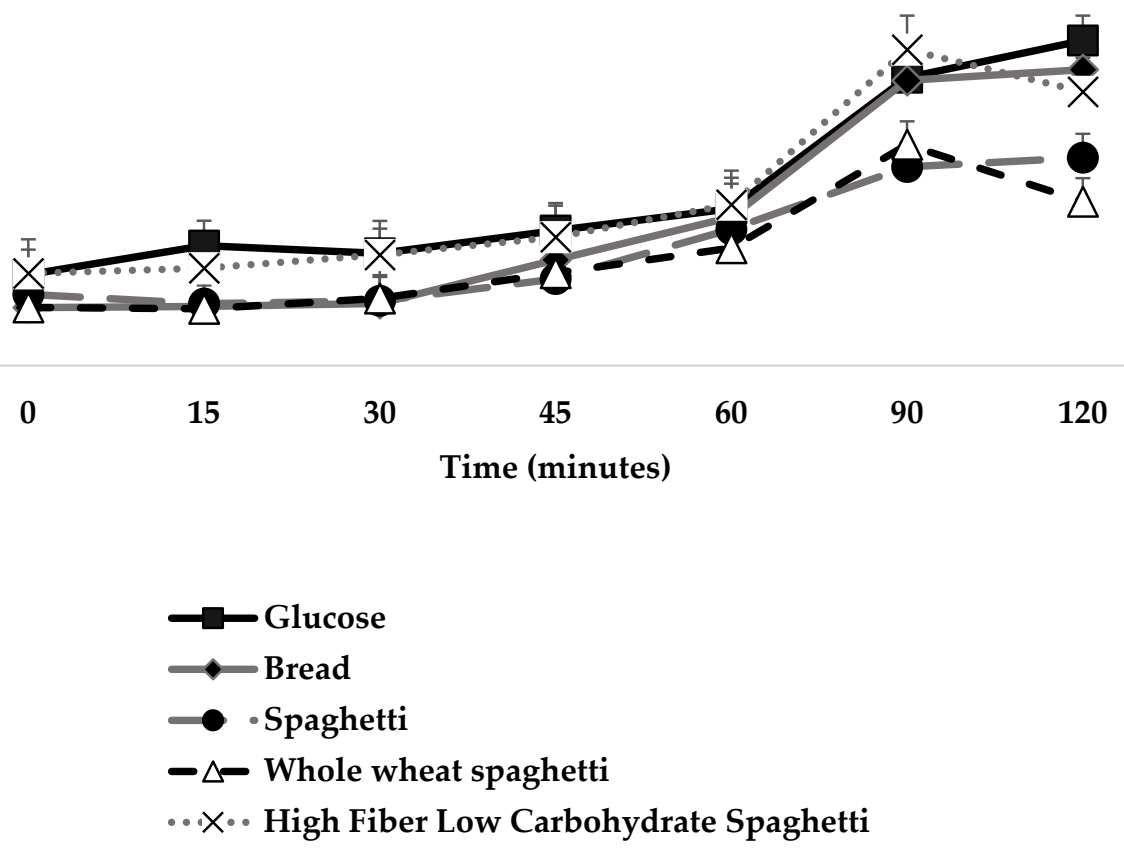

(B)

Figure 2. (A) Glycemic response after consumption of the reference food (D-glucose) and bread (white bread) and the three spaghetti food products $(n=14)$. Data are the means \pm S.E.M. Post hoc Tukey test, with Bonferroni correction, was conducted to determine test meal differences at each specific time. (B) Insulinemic response after consumption of the reference food (D-glucose) and bread (white bread) and the three spaghetti food products $(n=14)$. Data are the means \pm S.E.M. Post hoc Tukey test, with Bonferroni correction, was conducted to determine test meal differences at each specific time. 


\section{Discussion}

By applying the standard GI methodology, this study produced data for equally thin spaghetti pastas (No 7) differing significantly in dietary soluble fiber and protein content. The results showed that the glycemic responses of the three tested spaghetti pastas were significantly lower than the responses of a glucose drink or white bread as reference foods, without significant differences between them.

\subsection{Glycemic Index (GI) and Glycemic Responses: Fiber and Protein Implications}

In general, the consumption of spaghetti pasta, particularly wholegrain spaghetti or novel spaghetti pastas containing high amounts of soluble fiber and plant protein, is linked to ameliorated glycemic response and improved insulin sensitivity, partly attributed to fiber [31]. Short-term intervention studies [32] and epidemiological and prospective studies have consistently shown an association between wholegrain consumption and a reduced mortality and metabolic disease risk [33,34]. A short-term study using continuous glucose monitoring showed that young healthy adults following a low GI diet had lower average day-long glycemia compared with a macronutrient-matched high GI diet, indicating the use of low GI diets to reduce the risk of developing glucose intolerance [35]. The use of GI for the classification of carbohydrate-rich foods has been endorsed by the FAO/WHO, who recommended that the GI of foods should be considered together with information about food composition to guide food choices [2]. Consumption of foods and meals that induce a lower glycemic response and delay gastric emptying, thus leading to decreased insulin requirements and postprandial glucose excursions, has been proposed as an important strategy to ameliorate postprandial hyperglycemia and insulin resistance [36]. Such foods typically contain high fiber, particularly soluble fiber, low amounts of easily absorbable carbohydrates, and are high in proteins [36-38]. It has been shown that consumption of fibers (i.e., beta-glucans, whole-grain cereals) may slow the rates of gastric emptying and intestinal glucose absorption, thus reducing postprandial glucose responses in a dosedependent manner [39]. Lowering the GI of a food may be significant as it has been shown that consumption of low GI foods may be sufficient to achieve a lower glycemic response from one meal to the next [40-43]. In 2017, the American Diabetes Association proposed consuming daily wholegrain cereal products along with weight loss for the prevention of type 2 diabetes [44].

The GI of spaghetti pastas may be affected by many factors, including the addition of soluble fiber, resistant starch, fats, proteins, processing, preparation and cooking methods, the physical form of the food, the type of sugars and starch, the ripeness or the maturity of the raw ingredients, etc. $[6,18,23,24,45,46]$. It has been shown that different brands of the same type of pasta, i.e., shape or size of circumference, may look and taste almost the same, but differences in the type of flour used, the technological aspects (time/temperature/humidity drying cycles; extrusion dies) and the cooking time can result in differences in the degree of starch gelatinization and consequently the GI values $[18,26]$. This was evident comparing the GIs of three analyzed spaghetti (i.e., regular, GI $=51$; No 5, GI = 33; and No 12, GI = 50), all producing lower GIs [18]. The current evaluation showed that all three types of spaghetti pastas (semolina spaghetti, wholegrain spaghetti, and semolina spaghetti high in soluble fiber and low in carbohydrates) can be classified as equally low GI food products with a GI of 33, 38, and 41, respectively. All three had significantly lower incremental glucose responses, glucose excursions, and GIs as compared to the reference foods. Our results are in agreement with others reporting that spaghetti produces a significantly smaller rise in blood glucose compared to breads (whole grain or white) or other types of pasta, indicating that differences in food form, independent of fiber content, may have marked effects on postprandial glycemia [18,24,26,45,47-49]. Our results also agree with the International Food Tables [50,51]. One study examining the effects of semolina spaghetti, wholegrain spaghetti, wheat-based mee pok noodles, and rice, showed that both spaghetti pastas led to significantly lower glycemic and insulinemic responses compared to noodles and rice, without differences between the spaghetti pastas, 
although the wholegrain spaghetti studied contained more than double the amount of fiber compared to regular semolina spaghetti pasta [49]. Notably, in the current evaluation, there was no significant difference in glycemic responses between the three spaghetti pastas, although WS and HFlowCS contained almost four times and twelve times more, respectively, the amount of fiber. All three spaghetti pastas also produced a lower GL value compared to the reference foods without significant differences between them. Thus, our data do not support the popular idea of a reduced glycemic response elicited by increasing fiber content in foods, such as in the case of spaghetti pastas, which is in agreement with others $[26,46,47,49,52,53]$. The inconsistencies reported for fibers' effects on postprandial glycemia may be due to the fact that when soluble fibers are added to foods, their molecular weight vary and interactions with other compounds can occur. It may also be that only certain types of fiber, mainly soluble (i.e., vegetable gums, derived from fruits, legumes, and psyllium), may influence the GI of foods through a reduced rate of gastric emptying as they make the chyme (partly digested food coming from the stomach) more viscous [46,53]. Other possible explanations may be that glycemic response is not significantly related to soluble dietary fiber content or that soluble fibers' effects are masked when they interact with other compounds, or that they are not as important in controlling postprandial glycemia. Finally, it may also be considered that the postprandial glucose-lowering effects of fiber, particularly soluble fiber, will be markedly observed when added to some high GI foods, such as breads $[46,53,54]$, and not to low GI foods, such as spaghetti pastas.

There is evidence that the acute glycemic response to whole-grain foods is greater when grains have been finely milled [55]. One study showed that the glycemic response to four different whole-grain wheat breads was related to the degree of grain processing in adults with type 2 diabetes [56]. Thus, the lack of differences observed between and among the three spaghetti pastas investigated in the current evaluation may be due to the use of hard wheat flours in all of them [26]. It has been suggested that the protein-starch matrix itself, owing to the production process, is the main basis for the reduced glycemic responses of pasta and this warrants further research [49]. It may also be that the food structure of spaghetti is the main driver of its favorable metabolic properties [49].

Another reason for the beneficial effects of spaghetti products on postprandial glycemia and GI may be due to their larger particle size which may be related to the altered starch surface area available for enzymatic action [57,58]. Our group [23] and others [59,60] have shown that bran larger particle size leads to lower GI, GL, and glycemic responses compared to bran smaller particle size. Gluten partially protects starch from digestion [6]. Thus, the increased particle size may lead to decreased starch susceptibility to hydrolysis, lower starch digestion, and delayed gastric emptying [59-61]. It has been shown that the rate of gastric emptying is not influenced by soluble fibers, but by other factors, such as bran particle size and the meal's energy density [62]. A study investigating the rate of gastric emptying and the glycemic response after consumption of wheat and oat-based breakfast meals showed that wheat meal caused delayed gastric emptying and improved glycemic response compared to oatmeal, despite the presence of $\beta$-glucan in oats [62]. Moreover, the beneficial results of spaghetti products on postprandial glycemia may be due to their lower hydration status, since it has been shown that foods with lower hydration (i.e., $70 \%$ of water content) produced the lowest estimated GI and GL values [17]. We have previously reported a negative correlation of dough water content with GI [23].

Meal composition and ingestion of low GI foods, particularly when consumed along with protein and/or fat, reduce postprandial glucose and insulin responses, thus improving insulin sensitivity [37,38,63-66], which may be due to their insulinotropic effects. It has been reported that $50 \mathrm{~g}$ protein addition to a carbohydrate food, such as white bread, can significantly lower the GI of the meal by $27 \%$ and the incremental area under the curve for glucose by $27 \%$ [66]. However, another study in patients with type 1 diabetes examining the effects of two types of pasta, a higher protein pasta containing $10 \mathrm{~g}$ protein/serving and regular pasta with $7 \mathrm{~g}$ protein/serving compared to extra-long grain white rice (all meals containing $42 \mathrm{~g}$ carbohydrates) on glucose responses using continuous glucose 
monitoring, showed that both pasta compared to white rice led to significantly lower peak glucose levels and lower total glucose AUC, without significant differences between them [48]. Other studies suggested that pasta formulated with legume flours, red lentils, grass rea and chickpea, produced lower GIs (GI ranging from 20 to 58) compared to wheat pasta (GI ranging from 53 to 73), possibly due to the two to three times higher levels in fiber and proteins (24-27 g/100 g) with respect to wheat pasta (14 g protein/100 g) $[67,68]$. Two studies from our group, an acute [69] and a short-term (8 weeks duration) [70] cross-over randomized clinical trial, and a 2013 meta-analysis of studies ranging from 4-24 weeks, reported that high-protein eating plans (25-32\% of total energy vs. 15-20\%) resulted in two kilograms greater weight loss, better maintenance of muscle mass and $0.5 \%$ greater improvements in $\mathrm{HbA} 1 \mathrm{c}$, without significant decreases in fasting glucose levels [71]. In our current evaluation, we did not observe differences in postprandial glycemic responses between the three tested spaghetti pastas, which is in agreement with others $[49,72]$, although the tested spaghetti pastas had marked but not clinically significant differences in protein content $(7 \mathrm{~g}$ in boiled $\mathrm{S}$ vs. $13 \mathrm{~g}$ in boiled WS vs. $10 \mathrm{~g}$ in boiled HFlowCS). This observation could also be because the postprandial glucose-lowering effects of protein, would be more clearly observed when added to high GI foods, such as breads, and not to low GI foods, such as spaghetti pastas.

\subsubsection{Blood and Salivary Insulin Responses}

One study found an improved insulin response after semolina spaghetti compared to wholegrain spaghetti which confirmed that a higher fiber content in spaghetti did not affect the metabolic responses [49]. Although salivary insulin is not commonly used in clinical studies, it has been shown to be a non-invasive tool for assessing hormones' concentrations $[73,74]$ and has been positively correlated to serum insulin in healthy young subjects with normal body weight and overweight/obesity $[30,73,74]$ and in people with type 1 diabetes [75]. In the current evaluation, we did not observe differences between spaghetti pastas in postprandial salivary insulin concentrations, regardless of their fiber or protein content. Our results are in agreement with two studies showing no effects of particle size on insulin responses in healthy subjects $[23,76]$ but are in contrast with another study showing that larger particle size produced significantly lower insulin responses in people with type 2 diabetes [77]. The conflicting results may be due to the different study design, i.e., different bread formulations, and the population under study, i.e., healthy vs. subjects with type 2 diabetes. It is reasonable that it may be easier to detect differences in a population having hyperinsulinemia and insulin resistance compared to healthy young adults participating in our study.

\subsubsection{Blood Pressure}

Blood pressure was not found to be different at baseline and end of all trials between and among the test meals studied. It is well known that foods' salt content and addition of salt to foods have a significant impact on BP. In our study, all spaghetti test meals contained low amounts of sodium and were prepared in the same manner with unsalted water, which may explain the lack of differences between and among meals regarding BP. Moreover, our subjects were young and normotensive, which may also be significant factors for not observing acute differences in BP among and between test meals. Similarly, we did not observe acute differences in subjective appetite between and among test meals, regardless of their protein or fiber content, which may be due to the limited time frame of two hours duration of our study.

\subsection{Study Limitations and Advantages}

Among the limitations of the study, blood collection from the participants enabled measurements of plasma insulin and incretins. The strength of our study was the randomized crossover design where each subject served as his own control. 


\subsection{Practical Applications}

To the best of our knowledge, this study determined for the first time the GI of three different types of spaghetti pastas, differing significantly in soluble fiber and protein. Our study followed controlled circumstances for a GI protocol. Based on our results, spaghetti pastas, particularly whole grain, and novel ones with low total carbohydrates, high in soluble fiber and protein are advisable for the prevention of high blood glucose excursions and should be considered by people with overweight/obesity or type 2 diabetes. It should be stressed out that the novel type of spaghetti contains twelve times more dietary fibers compared to the simple spaghetti and triple the dietary fibers compared to the whole grain one. The high content of dietary fibers attributes to the overall daily intake of fibers, with a portion of $100 \mathrm{~g}$ covering almost $80 \%$ of the recommended daily intake of dietary fiber according to the WHO. Moreover, the HFLowCS can be a useful food item for patients with type 2 diabetes as in the same portion size with simple and whole-grain spaghetti, they take $65 \%$ and $30 \%$ less carbohydrates, resulting in a better glycemic response and lower need for insulin secretion. Moreover, the higher plant-based protein content alongside the high soluble dietary fiber makes the HFLowCS a novel food item with significant importance for the management of cardiometabolic risk and the overall health of the gut.

\section{Conclusions}

In conclusion, the results of this study confirmed that spaghetti pastas, regardless of their soluble fiber and/or protein content are low GI foods, producing lower postprandial glucose concentrations and lower glucose excursions in young healthy subjects, indicating that they are a suitable dietary alternative for glycemic control. Future long-term studies are needed to provide an insight regarding the mechanisms by which different types of pasta of varied formulations elicit a more favorable impact on the glycemic response in different population groups including subjects with type 2 diabetes and/or obesity. The efforts of the food industry to improve the nutrient density of foods and their impact on disease prevention, such as spaghetti containing twelve times more dietary fibers compared to regular spaghetti and three times more fiber compared to whole grain ones, are highly encouraged as they can aid significantly in covering almost $80 \%$ of the recommended daily intake of dietary fiber according to the WHO, whilst consuming 65\% less carbohydrates than regular spaghetti and 30\% less carbohydrates than whole-grain spaghetti in the same portion consumed. Consumption of spaghetti pasta, particularly whole-grain ones and novel ones with different formulations, high in soluble fibers and plant proteins, is an important strategy for glycemic control and prevention or dietary treatment of chronic diseases.

Author Contributions: E.P. conceptualized, designed the study, conducted statistical analysis and drafted the manuscript; M.X. and V.S. collected the data; M.G. and G.K. conducted the analysis of nutrients, available carbohydrates and fibers in all food products, contributed to manuscript preparation, and critically revised the manuscript; G.T. served as scientific counselor for salivary insulin measurement and assessment; E.M. served as scientific counselor for salivary insulin assessment; K.-A.P., G.D.D. and P.N.S. served as project scientific counselors to the project and critically revised the manuscript. All authors have read and agreed to the published version of the manuscript.

Funding: This research was partly funded by Melissa Kikizas S.A., Athens, Greece.

Institutional Review Board Statement: The study was conducted in accordance with the Declaration of Helsinki, and approved by the Ethics Committee (EIDE) of Agricultural University of Athens (protocol code 49 and date of approval 11/10/2021).

Informed Consent Statement: Informed consent was obtained from all subjects involved in the study.

Data Availability Statement: Not applicable.

Acknowledgments: The authors are grateful to the company Melissa Kikizas S.A. for partly funding this project and for providing us with the spaghetti pastas. The authors gratefully acknowledge Ioanna Mandala (imandala@aua.gr) and Panagiotis Chaloulos, student (pxalou@gmail.com) for valuable discussions on issues pertaining to starch. The authors gratefully acknowledge Vassilis 


\begin{abstract}
Alsab, undergraduate student, and Panagiotis Chaloulos, PhD student, for helping with available carbohydrate measurements and nutrient analysis; Maria Kontomitrou and Christina Oikonomou for helping with the GI intervention trial; Elena Pavlidi, for helping with salivary insulin measurements; Christina Athanasaki, Konstantinos Spanakis, Marinos Kontos and Nickolaos Gampierakis, all undergraduate students for helping with the GI intervention trial and insulin data collection, as part of their undergraduate Thesis project.
\end{abstract}

Conflicts of Interest: The authors declare no conflict of interest.

\title{
References
}

1. ISO 26642; Food Products-Determination of the Glycaemic Index (GI) and Recommendation for Food Classification. International Standards Organization: Geneva, Switzerland, 2010.

2. FAO and WHO. Carbohydrates in human nutrition. Report of a Joint FAO/WHO Expert Consultation. FAO Food Nutr. Pap. 1998, $66,1-140$.

3. Augustin, L.S.; Kendall, C.W.; Jenkins, D.J.; Willett, W.C.; Astrup, A.; Barclay, A.W.; Bjorck, I.; Brand-Miller, J.C.; Brighenti, F.; Buyken, A.E.; et al. Glycemic index, glycemic load and glycemic response: An International Scientific Consensus Summit from the International Carbohydrate Quality Consortium (ICQC). Nutr. Metab. Cardiovasc. Dis. 2015, 25, 795-815. [CrossRef] [PubMed]

4. Brouns, F.; Bjorck, I.; Frayn, K.N.; Gibbs, A.L.; Lang, V.; Slama, G.; Wolever, T.M. Glycaemic index methodology. Nutr. Res. Rev 2005, 18, 145-171. [CrossRef]

5. Wolever, T.M.; Jenkins, D.J.; Jenkins, A.L.; Josse, R.G. The glycemic index: Methodology and clinical implications. Am. J. Clin. Nutr. 1991, 54, 846-854. [CrossRef] [PubMed]

6. Fardet, A.; Leenhardt, F.; Lioger, D.; Scalbert, A.; Remesy, C. Parameters controlling the glycaemic response to breads. Nutr. Res. Rev. 2006, 19, 18-25. [CrossRef] [PubMed]

7. Ceriello, A.; Esposito, K.; Piconi, L.; Ihnat, M.A.; Thorpe, J.E.; Testa, R.; Boemi, M.; Giugliano, D. Oscillating glucose is more deleterious to endothelial function and oxidative stress than mean glucose in normal and type 2 diabetic patients. Diabetes 2008, 57, 1349-1354. [CrossRef]

8. Monnier, L.; Colette, C. Target for glycemic control: Concentrating on glucose. Diabetes Care 2009, 32 (Suppl. 2), S199-S204. [CrossRef]

9. Bao, J.; Atkinson, F.; Petocz, P.; Willett, W.C.; Brand-Miller, J.C. Prediction of postprandial glycemia and insulinemia in lean, young, healthy adults: Glycemic load compared with carbohydrate content alone. Am. J. Clin. Nutr. 2011, 93, 984-996. [CrossRef]

10. Barclay, A.W.; Petocz, P.; McMillan-Price, J.; Flood, V.M.; Prvan, T.; Mitchell, P.; Brand-Miller, J.C. Glycemic index, glycemic load, and chronic disease risk-a meta-analysis of observational studies. Am. J. Clin. Nutr. 2008, 87, 627-637. [CrossRef]

11. Greenwood, D.C.; Threapleton, D.E.; Evans, C.E.; Cleghorn, C.L.; Nykjaer, C.; Woodhead, C.; Burley, V.J. Glycemic index, glycemic load, carbohydrates, and type 2 diabetes: Systematic review and dose-response meta-analysis of prospective studies. Diabetes Care 2013, 36, 4166-4171. [CrossRef]

12. FAO and WHO. Carbohydrate and nutrition. Nurs. Stand. 1998, 12, 32-33.

13. Evert, A.B.; Boucher, J.L.; Cypress, M.; Dunbar, S.A.; Franz, M.J.; Mayer-Davis, E.J.; Neumiller, J.J.; Nwankwo, R.; Verdi, C.L.; Urbanski, P.; et al. Nutrition therapy recommendations for the management of adults with diabetes. Diabetes Care 2013, 36, 3821-3842. [CrossRef] [PubMed]

14. Chiavaroli, L.; Lee, D.; Ahmed, A.; Cheung, A.; Khan, T.A.; Mejia, S.B.; Mirrahimi, A.; Jenkins, D.J.A.; Livesey, G.; Wolever, T.M.S.; et al. Effect of low glycaemic index or load dietary patterns on glycaemic control and cardiometabolic risk factors in diabetes: Systematic review and meta-analysis of randomised controlled trials. BMJ 2021, 374, n1651. [CrossRef] [PubMed]

15. Thomas, D.; Elliott, E.J. Low glycaemic index, or low glycaemic load, diets for diabetes mellitus. Cochrane Database Syst. Rev. 2009, 1. [CrossRef] [PubMed]

16. Wheeler, M.L.; Dunbar, S.A.; Jaacks, L.M.; Karmally, W.; Mayer-Davis, E.J.; Wylie-Rosett, J.; Yancy, W.S., Jr. Macronutrients, food groups, and eating patterns in the management of diabetes: A systematic review of the literature, 2010. Diabetes Care 2012, 35, 434-445. [CrossRef]

17. de la Hera, E.; Rosell, C.M.; Gomez, M. Effect of water content and flour particle size on gluten-free bread quality and digestibility. Food Chem. 2014, 151, 526-531. [CrossRef]

18. Scazzina, F.; Dall'Asta, M.; Casiraghi, M.C.; Sieri, S.; Del Rio, D.; Pellegrini, N.; Brighenti, F. Glycemic index and glycemic load of commercial Italian foods. Nutr. Metab. Cardiovasc. Dis. 2016, 26, 419-429. [CrossRef]

19. Jenkins, A.L.; Jenkins, D.J.; Zdravkovic, U.; Wursch, P.; Vuksan, V. Depression of the glycemic index by high levels of beta-glucan fiber in two functional foods tested in type 2 diabetes. Eur. J. Clin. Nutr. 2002, 56, 622-628. [CrossRef]

20. Ray, K.S.; Singhania, P.R. Glycemic and insulinemic responses to carbohydrate rich whole foods. J. Food Sci. Technol. 2014, 51,347-352. [CrossRef]

21. Papakonstantinou, E.; Orfanakos, N.; Farajian, P.; Kapetanakou, A.E.; Makariti, I.P.; Grivokostopoulos, N.; Ha, M.A.; Skandamis, P.N. Short-term effects of a low glycemic index carob-containing snack on energy intake, satiety, and glycemic response in normal-weight, healthy adults: Results from two randomized trials. Nutrition 2017, 42, 12-19. [CrossRef] 
22. Gourdomichali, T.; Papakonstantinou, E. Short-term effects of six Greek honey varieties on glycemic response: A randomized clinical trial in healthy subjects. Eur. J. Clin. Nutr. 2018, 72, 1709-1716. [CrossRef] [PubMed]

23. Papakonstantinou, E.; Chaloulos, P.; Papalexi, A.; Mandala, I. Effects of bran size and carob seed flour of optimized bread formulas on glycemic responses in humans: A randomized clinical trial. J. Funct. Foods 2018, 46, 345-355.

24. Di Pede, G.; Dodi, R.; Scarpa, C.; Brighenti, F.; Dall'Asta, M.; Scazzina, F. Glycemic Index Values of Pasta Products: An Overview. Foods 2021, 10, 2541. [CrossRef] [PubMed]

25. Wolever, T.M.; Vorster, H.H.; Bjorck, I.; Brand-Miller, J.; Brighenti, F.; Mann, J.I.; Ramdath, D.D.; Granfeldt, Y.; Holt, S.; Perry, T.L.; et al. Determination of the glycaemic index of foods: Interlaboratory study. Eur. J. Clin. Nutr. 2003, 57, 475-482. [CrossRef] [PubMed]

26. Pandolfo, A.; Messina, B.; Russo, G. Evaluation of Glycemic Index of Six Different Samples of Commercial and Experimental Pasta Differing in Wheat Varieties and Production Processes. Foods 2021, 10, 2221. [CrossRef]

27. Urbaniak, G.C.; Plous, S. Research Randomizer (version 4.0) [Computer Software]. Available online: http:/ / www.randomizer.org (accessed on 1 March 2021)

28. Kaplan, E.A. The effect of durum wheat genotypes on cooking quality of pasta. Eur. J. Food Res. Technol. 2022, 248, 815-824. [CrossRef]

29. Flint, A.; Raben, A.; Blundell, J.E.; Astrup, A. Reproducibility, power and validity of visual analogue scales in assessment of appetite sensations in single test meal studies. Int. J. Obes. Relat. Metab. Disord. 2000, 24, 38-48. [CrossRef]

30. Myette-Cote, E.; Baba, K.; Brar, R.; Little, J.P. Detection of Salivary Insulin Following Low versus High Carbohydrate Meals in Humans. Nutrients 2017, 9, 1204. [CrossRef]

31. Schulze, M.B.; Liu, S.; Rimm, E.B.; Manson, J.E.; Willett, W.C.; Hu, F.B. Glycemic index, glycemic load, and dietary fiber intake and incidence of type 2 diabetes in younger and middle-aged women. Am. J. Clin. Nutr. 2004, 80, 348-356. [CrossRef]

32. Karl, J.P.; Meydani, M.; Barnett, J.B.; Vanegas, S.M.; Goldin, B.; Kane, A.; Rasmussen, H.; Saltzman, E.; Vangay, P.; Knights, D.; et al. Substituting whole grains for refined grains in a 6-wk randomized trial favorably affects energy-balance metrics in healthy men and postmenopausal women. Am. J. Clin. Nutr. 2017, 105, 589-599. [CrossRef]

33. Wu, H.; Flint, A.J.; Qi, Q.; van Dam, R.M.; Sampson, L.A.; Rimm, E.B.; Holmes, M.D.; Willett, W.C.; Hu, F.B.; Sun, Q. Association between dietary whole grain intake and risk of mortality: Two large prospective studies in US men and women. JAMA Intern. Med. 2015, 175, 373-384. [CrossRef] [PubMed]

34. Jacobs, D.R., Jr.; Andersen, L.F.; Blomhoff, R. Whole-grain consumption is associated with a reduced risk of noncardiovascular, noncancer death attributed to inflammatory diseases in the Iowa Women's Health Study. Am. J. Clin. Nutr. 2007, 85, 1606-1614. [CrossRef] [PubMed]

35. Hon, H.W.H.; Wong, T.H.T.; Tse, I.M.Y.; Louie, J.C.Y. The effect of a low glycaemic index diet on reducing day-long glycaemia in healthy young adults: A randomized crossover trial. Diabetes Obes. Metab. 2020, 22, 2398-2407. [CrossRef] [PubMed]

36. Papakonstantinou, E.; Oikonomou, C.; Nychas, G.; Dimitriadis, G.D. Effects of Diet, Lifestyle, Chrononutrition and Alternative Dietary Interventions on Postprandial Glycemia and Insulin Resistance. Nutrients 2022, 14, 823. [CrossRef]

37. Brynes, A.E.; Adamson, J.; Dornhorst, A.; Frost, G.S. The beneficial effect of a diet with low glycaemic index on 24 h glucose profiles in healthy young people as assessed by continuous glucose monitoring. Br. J. Nutr. 2005, 93, 179-182. [CrossRef]

38. Vlachos, D.; Malisova, S.; Lindberg, F.A.; Karaniki, G. Glycemic Index (GI) or Glycemic Load (GL) and Dietary Interventions for Optimizing Postprandial Hyperglycemia in Patients with T2 Diabetes: A Review. Nutrients 2020, 12, 561. [CrossRef]

39. Kim, H.; Stote, K.S.; Behall, K.M.; Spears, K.; Vinyard, B.; Conway, J.M. Glucose and insulin responses to whole grain breakfasts varying in soluble fiber, beta-glucan: A dose response study in obese women with increased risk for insulin resistance. Eur. $J$. Nutr. 2009, 48, 170-175. [CrossRef]

40. Ibrugger, S.; Vigsnaes, L.K.; Blennow, A.; Skuflic, D.; Raben, A.; Lauritzen, L.; Kristensen, M. Second meal effect on appetite and fermentation of wholegrain rye foods. Appetite 2014, 80, 248-256. [CrossRef]

41. Nilsson, A.C.; Ostman, E.M.; Granfeldt, Y.; Bjorck, I.M. Effect of cereal test breakfasts differing in glycemic index and content of indigestible carbohydrates on daylong glucose tolerance in healthy subjects. Am. J. Clin. Nutr. 2008, 87, 645-654. [CrossRef]

42. Nilsson, A.C.; Ostman, E.M.; Holst, J.J.; Bjorck, I.M. Including indigestible carbohydrates in the evening meal of healthy subjects improves glucose tolerance, lowers inflammatory markers, and increases satiety after a subsequent standardized breakfast. $J$. Nutr. 2008, 138, 732-739. [CrossRef]

43. Rosen, L.A.; Ostman, E.M.; Bjorck, I.M. Postprandial glycemia, insulinemia, and satiety responses in healthy subjects after whole grain rye bread made from different rye varieties. 2. J. Agric. Food Chem. 2011, 59, 12149-12154. [CrossRef] [PubMed]

44. ADA. American Diabetes Association. 4. Lifestyle Management. Diabetes Care 2017, 40, S33-S43. [CrossRef] [PubMed]

45. Wolever, T.M.; Jenkins, D.J.; Kalmusky, J.; Giordano, C.; Giudici, S.; Jenkins, A.L.; Thompson, L.U.; Wong, G.S.; Josse, R.G. Glycemic response to pasta: Effect of surface area, degree of cooking, and protein enrichment. Diabetes Care 1986, 9, 401-404. [CrossRef] [PubMed]

46. Scazzina, F.; Siebenhandl-Ehn, S.; Pellegrini, N. The effect of dietary fibre on reducing the glycaemic index of bread. Br. J. Nutr. 2013, 109, 1163-1174. [CrossRef]

47. Jenkins, D.J.; Wolever, T.M.; Jenkins, A.L.; Lee, R.; Wong, G.S.; Josse, R. Glycemic response to wheat products: Reduced response to pasta but no effect of fiber. Diabetes Care 1983, 6, 155-159. [CrossRef] 
48. Zavitsanou, S.; Massa, J.; Deshpande, S.; Pinsker, J.E.; Church, M.M.; Andre, C.; Doyle Iii, F.J.; Michelson, A.; Creason, J.; Dassau, E.; et al. The Effect of Two Types of Pasta Versus White Rice on Postprandial Blood Glucose Levels in Adults with Type 1 Diabetes: A Randomized Crossover Trial. Diabetes Technol. Ther. 2019, 21, 485-492. [CrossRef]

49. Camps, S.G.; Lim, J.; Koh, M.X.N.; Henry, C.J. The Glycaemic and Insulinaemic Response of Pasta in Chinese and Indians Compared to Asian Carbohydrate Staples: Taking Spaghetti Back to Asia. Nutrients 2021, 13, 451. [CrossRef]

50. Atkinson, F.S.; Brand-Miller, J.C.; Foster-Powell, K.; Buyken, A.E.; Goletzke, J. International tables of glycemic index and glycemic load values 2021: A systematic review. Am. J. Clin. Nutr. 2021. [CrossRef]

51. Atkinson, F.S.; Foster-Powell, K.; Brand-Miller, J.C. International tables of glycemic index and glycemic load values: 2008. Diabetes Care 2008, 31, 2281-2283. [CrossRef]

52. Wolever, T.M. Relationship between dietary fiber content and composition in foods and the glycemic index. Am. J. Clin. Nutr. 1990, 51, 72-75. [CrossRef]

53. Bjorck, I.; Elmstahl, H.L. The glycaemic index: Importance of dietary fibre and other food properties. Proc. Nutr. Soc. 2003, 62, 201-206. [CrossRef] [PubMed]

54. Ludwig, D.S.; Hu, F.B.; Tappy, L.; Brand-Miller, J. Dietary carbohydrates: Role of quality and quantity in chronic disease. BMJ 2018, 361, k2340. [CrossRef]

55. Tosh, S.M.; Chu, Y. Systematic review of the effect of processing of whole-grain oat cereals on glycaemic response. Br. J. Nutr. 2015, 114, 1256-1262. [CrossRef]

56. Reynolds, A.N.; Mann, J.; Elbalshy, M.; Mete, E.; Robinson, C.; Oey, I.; Silcock, P.; Downes, N.; Perry, T.; Te Morenga, L. Wholegrain Particle Size Influences Postprandial Glycemia in Type 2 Diabetes: A Randomized Crossover Study Comparing Four Wholegrain Breads. Diabetes Care 2020, 43, 476-479. [CrossRef] [PubMed]

57. Blasel, H.M.; Hoffman, P.C.; Shaver, R.D. Degree of starch access: An enzymatic method to determine starch degradation potential of corn grain and corn silage. Anim. Feed. Sci. Technol. 2006, 128, 96-107. [CrossRef]

58. Parada, J.; Aguilera, J.M. Review: Starch matrices and the glycemic response. Food Sci. Technol. Int. 2011, 17, 187-204. [CrossRef]

59. Holt, S.H.; Miller, J.B. Particle size, satiety and the glycaemic response. Eur. J. Clin. Nutr. 1994, 48, 496-502. [PubMed]

60. Jenkins, D.J.; Wolever, T.M.; Buckley, G.; Lam, K.Y.; Giudici, S.; Kalmusky, J.; Jenkins, A.L.; Patten, R.L.; Bird, J.; Wong, G.S.; et al. Low-glycemic-index starchy foods in the diabetic diet. Am. J. Clin. Nutr. 1988, 48, 248-254. [CrossRef]

61. Jenkins, D.J.; Wolever, T.M.; Jenkins, A.L. Starchy foods and glycemic index. Diabetes Care 1988, 11, 149-159. [CrossRef] [PubMed]

62. Gopirajah, R.; Raichurkar, K.P.; Wadhwa, R.; Anandharamakrishnan, C. The glycemic response to fibre rich foods and their relationship with gastric emptying and motor functions: An MRI study. Food Funct. 2016, 7, 3964-3972. [CrossRef]

63. Jenkins, D.J.; Wolever, T.M.; Collier, G.R.; Ocana, A.; Rao, A.V.; Buckley, G.; Lam, Y.; Mayer, A.; Thompson, L.U. Metabolic effects of a low-glycemic-index diet. Am. J. Clin. Nutr. 1987, 46, 968-975. [CrossRef] [PubMed]

64. Nesti, L.; Mengozzi, A.; Trico, D. Impact of Nutrient Type and Sequence on Glucose Tolerance: Physiological Insights and Therapeutic Implications. Front. Endocrinol. 2019, 10, 144. [CrossRef] [PubMed]

65. Trico, D.; Natali, A. Modulation of postprandial glycemic responses by noncarbohydrate nutrients provides novel approaches to the prevention and treatment of type 2 diabetes. Am. J. Clin. Nutr. 2017, 106, 701-702. [CrossRef]

66. Meng, H.; Matthan, N.R.; Ausman, L.M.; Lichtenstein, A.H. Effect of macronutrients and fiber on postprandial glycemic responses and meal glycemic index and glycemic load value determinations. Am. J. Clin. Nutr. 2017, 105, 842-853. [CrossRef] [PubMed]

67. Turco, I.; Bacchetti, T.; Morresi, C.; Padalino, L.; Ferretti, G. Polyphenols and the glycaemic index of legume pasta. Food Funct. 2019, 10, 5931-5938. [CrossRef]

68. Goni, I.; Valentil-Gamazo, C. Chickpea flour ingredient slows glycemic response to pasta in healthy volunteers. Food Chem. 2003, 81, 511-515. [CrossRef]

69. Papakonstantinou, E.; Triantafillidou, D.; Panagiotakos, D.B.; Iraklianou, S.; Berdanier, C.D.; Zampelas, A. A high protein low fat meal does not influence glucose and insulin responses in obese individuals with or without type 2 diabetes. J. Hum. Nutr. Diet 2010, 23, 183-189. [CrossRef]

70. Papakonstantinou, E.; Triantafillidou, D.; Panagiotakos, D.B.; Koutsovasilis, A.; Saliaris, M.; Manolis, A.; Melidonis, A.; Zampelas, A. A high-protein low-fat diet is more effective in improving blood pressure and triglycerides in calorie-restricted obese individuals with newly diagnosed type 2 diabetes. Eur. J. Clin. Nutr. 2010, 64, 595-602. [CrossRef]

71. Dong, J.Y.; Zhang, Z.L.; Wang, P.Y.; Qin, L.Q. Effects of high-protein diets on body weight, glycaemic control, blood lipids and blood pressure in type 2 diabetes: Meta-analysis of randomised controlled trials. Br. J. Nutr. 2013, 110, 781-789. [CrossRef]

72. Scazzina, F.; Del Rio, D.; Pellegrini, N.; Brighenti, F. Sourdough bread: Starch digestibility and postprandial glycemic response. J. Cereal Sci. 2009, 49, 419-421. [CrossRef]

73. Desai, G.S.; Mathews, S.T. Saliva as a non-invasive diagnostic tool for inflammation and insulin-resistance. World. J. Diabetes 2014, 5, 730-738. [CrossRef] [PubMed]

74. Fabre, B.; Maccallini, G.; Oneto, A.; Gonzalez, D.; Hirschler, V.; Aranda, C.; Berg, G. Measurement of fasting salivary insulin and its relationship with serum insulin in children. Endocr. Connect. 2012, 1, 58-61. [CrossRef] [PubMed]

75. Pasic, J.; Pickup, J.C. Salivary insulin in normal and type I diabetic subjects. Diabetes Care 1988, 11, 489-494. [CrossRef] [PubMed] 
76. Eelderink, C.; Noort, M.W.J.; Sozer, N.; Koehorst, M.; Holst, J.J.; Deacon, C.F.; Rehfeld, J.F.; Poutanen, K.; Vonk, R.J.; Oudhuis, L.; et al. Difference in postprandial GLP-1 response despite similar glucose kinetics after consumption of wheat breads with different particle size in healthy men. Eur. J. Nutr. 2017, 56, 1063-1076. [CrossRef] [PubMed]

77. Jenkins, D.J.; Wesson, V.; Wolever, T.M.; Jenkins, A.L.; Kalmusky, J.; Guidici, S.; Csima, A.; Josse, R.G.; Wong, G.S. Wholemeal versus wholegrain breads: Proportion of whole or cracked grain and the glycaemic response. BMJ 1988, 297, 958-960. [CrossRef] 